\title{
Nelikümmend lindu eesti rahvausundis III
}

\section{$\underline{\text { Mall Hiiemäe }}$}

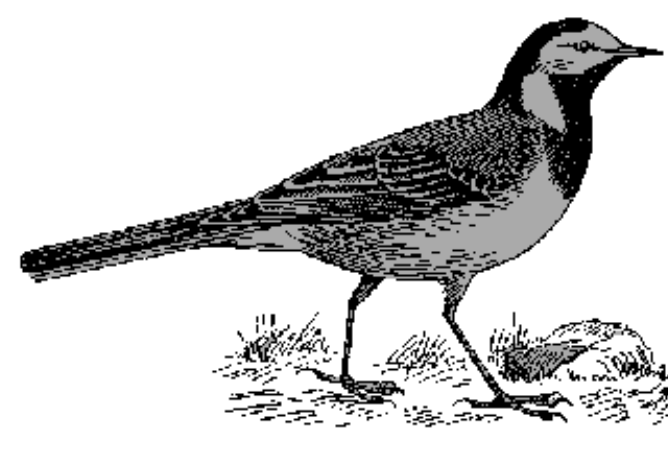

linavästrik Motacilla alba on linaõnne näitaja. Kehtib analoogiaprintsiip: kui teda kevadel lennul, puus, katusel, aia peal nähakse, kasvab hea lina, kui maas, siis lühike. Ka: kivi peal, siis pikk lina. Uskumuse järgi polnud linaõnne ka sellel, kes kevade hommikul *linnupetet pole võtnud ning söömata välja läks ning linalinnust "petetud" sai. Mõnel pool arvati, et kui linavästrik ilmub põllule või aeda seemne külvamise ajal tähendas, et ei lähe seeme kasvama. Üksikteated: lennus -süda rahul, hea õnn, maas - halb, süda kogu suve rahutu; nägija lööb suvel varbaid vastu kivi.

Linavästriku saabumist on ühte viidud jääminekuga veekogudel: linavästrik tallab, sõtkub (jalgadega), lõhub, põrutab (sabaga) jää katki.

Koos *kurega rändelendu tegevatest väikelindudest on kõige sagedamini nimetatud linavästrikut: tuleb kure tiiva peal, tiiva all, saba peal, jala peal, kanna peal, sulgede sees.

luik Muistendi järgi olnud üleni valge luik kunagi must, kuid ta sulestikus olevat veel alles üks must sulg, mille ta enne oma surma ära sööb. Oma kaasale olevat luik truu, kui see surmata, kukutavat ta end surnuks. Enne surma luik laulvat ning kes seda kuuleb, sureb varsti. Luige peale ei hakkavat püssikuul.

Luigeparve ülelendu kevadrändel on *sookurgedega võrreldes vähem ohustavaks peetud: "Kured kuulda, haned näha, luiged üle lugeda." Käitumisjuhend on samasugune nagu teiste suurte korrapärases parves lendavate rändlindude puhul: keelatud on näpuga näidata, see eksitaks neid. *Eksitamine toimub samade sõnadega mis sookure puhul: "Eksige, eksige!" või "Segapudru, segapudru!" Loendades, kas linde on paaris või paaritu arv, saab loendaja teada, kas ta endale sel aastal paarilise leiab.

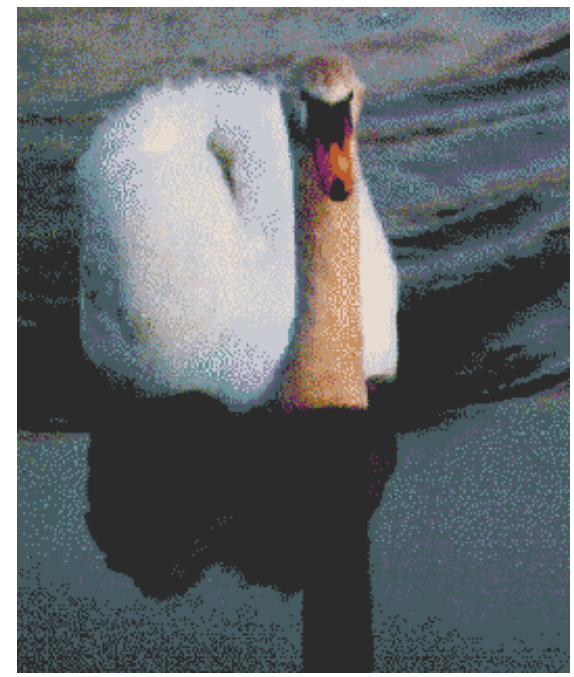
Usuti, et kes hommikul *linnupetet võtmata, s.o. söömata välja läheb ja esimest korda luikesid kuuldes niimoodi petetud saab, sel ei ole reisil ega teekonnal õnne. Luigeparvede saabumise aja järgi mererannikule arvestati jäämineku aega: "luigesitt peab kuu aega jää peal seisma." Madal lend tähendas, et kala püsib rohkem madalas vees. Sügisene kõrge ülelend on sügava lume, sooja talve enne, madal ülelend vähese lume, sooja talve enne. Sügisränne on märk peatsest lume mahatulekust.

Regilauludes on luik nagu paljud teised *linnud neiu sünonüüm. Epiteet luigeluust (laeva või lootsiku kohta) iseloomustab regilaulus eriti head sõiduvahendit (Laulutüüp "Luust laev"). 


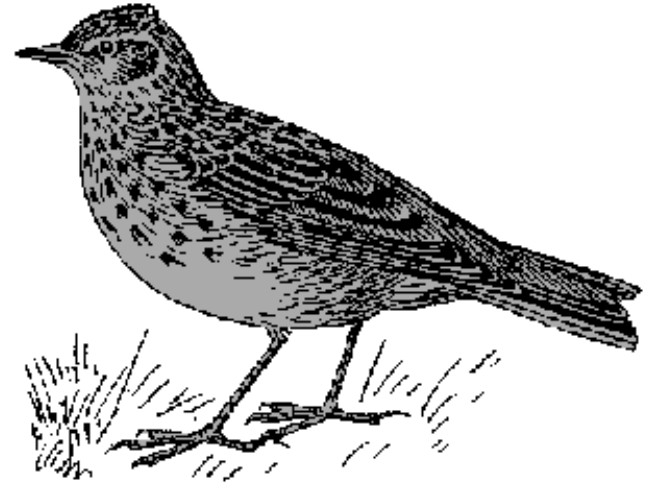

lõoke Lääne-eestilise levikuga tekkemuistendi järgi hakanud jumal ja *kurat linde looma. Jumala loodud lind tõusis õhku ja sai lõokeseks, kuradi loodu kukkus maha ning sellest sai *kärnkonn. Teise versiooni järgi näinud kurat jumala loodud lõokest ning püüdnud savist samuti lõokest teha, kuid sellest saanud kärnkonn.

Rahvauskumustes on lõoke talvel valge ning talvitub metsas või hange all. Talvelõokesteks $\sim$ talvisteks lõokesteks on siin peetud talikülalisi tsiitsitajalaste (vt. Emberizidae) sugukonnast - valgevärvilist hangelindu Plectrophenax

nivalis ja keltsalindu Calcarius lapponicus. Nende varajast ilmumist (kevadtalvel) on peetud pika ja külma kevade endeks. Nimetus "lõokesetali" märgib külmaperioodi pärast seda kui esimesi lõokesi juba nähtud oli. Jälgiti, millal lõokesed halliks muutuvad - siis oli oodata peatset lume sulamist ning kevade saabumist. Lääne-Eestist on esimest saabumist dateeritud madisepäevaga 24. II: "Lõokese keel lõigatakse lahti"; "lõokesesitt hange peal." Külma kevade enne oli lõokeste ilmumise küünlakuul, enne paastumaarjapäeva 25. III või noore kuuga.

au snd

Kiivitaja ja lõokesed, $1.6 \mathrm{Mb}$.au

Lõolaulu esimese kuulmisega seostub mõningaid uskumusi: hommikupoolel kuulmine toob rõõmu, õhtupool - kurbust eelolevald suveks; kui lõolaulu kuuldakse ilma et lindu nähtaks, seal (talus, külas) väsivad suvel hobused, lõolaulu kuuldes tuleb kukerpalli visata (või pikali heita), siis ei valuta suvel selg. Üksikteade lõolaulu lõppemise kohta kesksuvel: lõol läheb linaluu kurku.

Uskumused pesa kohta on vähetuntud. Kui lõopesasse tikk pista, "muneb kasvõi enese lõhki," et tikk kaetud saaks. Head lauluhäält arvati saavat linnumunade joomisest. Sellel, kes ilma *linnupetet võtmata, s.o. söömata kevadel hommikul välja läks ja esimest korda lõolaulu kuulis, oli üks võimalikke "pettasaamise" tagajärgi lauluhääle kaotamine.

metsis Tetrao urogallus. Metsis on muistendites üks metshaldja, demoniseerunud metsavaimu või kuradi ilmumiskujusid, ilmutades end enamasti kütile öösel lõkke ääres või päevasel jahiretkel. Näide: Kütt püüab laulvat metsiskukke (isametsist) edutult maha lasta. Kui ta oma püssi leivaraasudega laadib, on metsis äkki kadunud. Kütt kuuleb naisehäält ülevat, et vigasekslaskimise eest ei pea tal kunagi enam linnujahil õnne olema.

Kevadisel metsise- või *tedrejahil, mis eeldab öösel metsas viibimist, on aset leidnud paljud kogetud kohtumised üleloomulike olenditega.

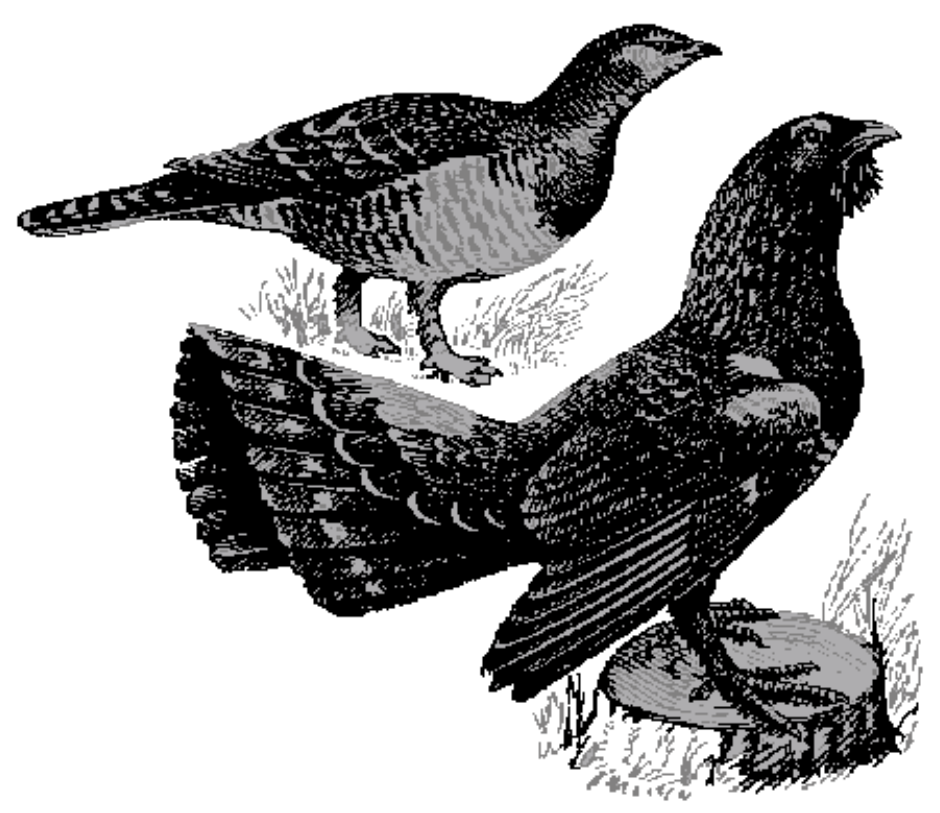




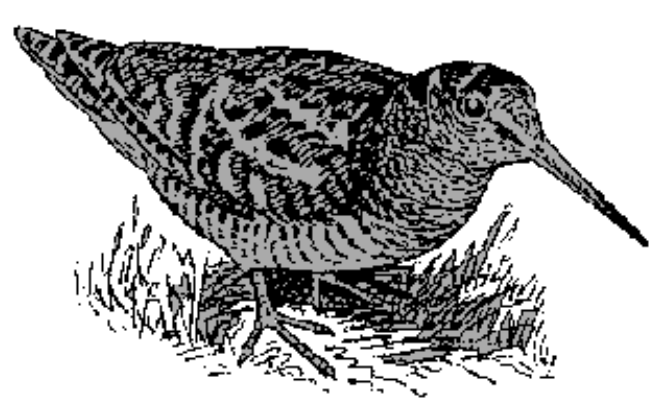

metskurvits Scolopax rusticola. Rahvauskumuse järgi arvati metskurvitsaid mätaste all talvituvat. Üksikteadetest ilmneb, et metskurvits pidi kevadel tagaotsast maitsvar piima - maaõli (-nestet) täis olema. Tema mängulennul kostvat häält arvati tulevat tagaotsast.

\section{nepp - vt. metskurvits \\ lapi kull - vt nõiakull}

nõiakull, ka lapi kull. Müütiline olend, keda nähti suure kulli näol linde (tetresid, nurmkanu, vareseid) taga ajamas. Seletusversioonid päritolu kohta on Põhja-Eestist:

1. Lapimaalt nõidusega kohale saadetud kull, kes peab linde Lapimaa inimestele söögiks ajama;

2. linnuks nõiutud inimene, kes enam rääkida ei saa;

3. nõid suure valge kullina, kel on punane hari peas;

4. vereta tehisolend, kel suled ümber ja takud ning jõhvid sees.

Lapimaa kulliks või nõiakulliks on peetud põhjapoolse levikuga invasioonilinde - lumekakke Nyctea scandiaca või lapi kakuks nimetatud habekakku Strix nebulosa. Nõiakulli võidi kohata kõige sagedamini linnujahil, surmata sai teda hõbekuuliga lastes.

peoleo Oriolus oriolus. Seletusmuistendi järele karjub peoleo enne vihma sellepärast, et tal pole luba mujalt vett juua kui puulehe pealt. Uskumuse järgi kuulutab peoleo ehk vihmakassi kräunuv häälitsus peatset vihma, vilistamine päikesepaistelist ilma. Üksikjuhtudel on peoleo ilmumist maja juurde laulma tõlgitsetud kui surmaennet või vallaslapse sündi.

Lõuna-Eestis on peoleo saabumine kevadel linakülvi orientiir. Sellele suunab ka häälitsuse alusel kujunenud nimetus. Peoleo, pihu tähendab eesti keeles peoleod; linapeo, linapihu lina mõõduühikut (peotäie jagu linakiudu). Külviks võetud linaseemneid on soovitatud läbi peoleo pesa lasta, et kasvaksid head kollased linad. Lõuna-eestiline on uskumus, et kes *linnupetet võtmata, s.o. söömata hommikul välja läheb ja

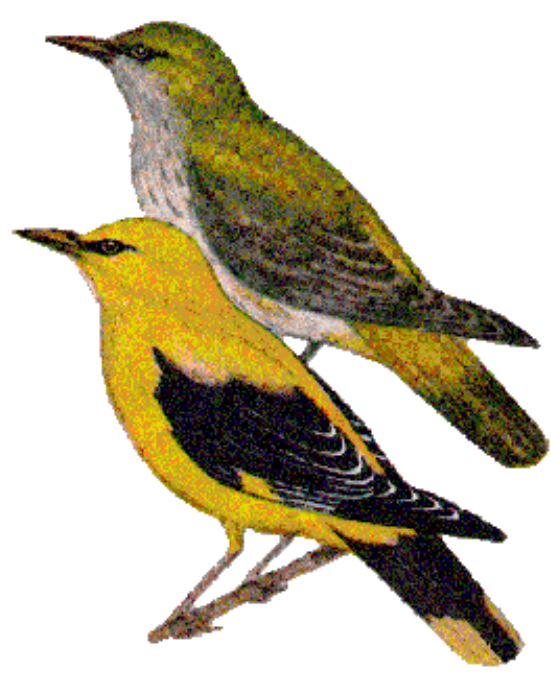
esimest korda hommikul peoleo laulu kuuleb, sel ei ole linakasvatuses õnne.

punarind (vt. lepalind) Erithacus rubecula. Rahvakeeles kannab punarind *lepalinnu nimetust. Tekkemuistendi järgi on see väike hall linnuke punase kurgualuse saanud Jeesuse verest, kui püüdis tema ihust ristinaelu välja nokkida. Analoogne süpee seletab leevikese punase põlle saamist. 


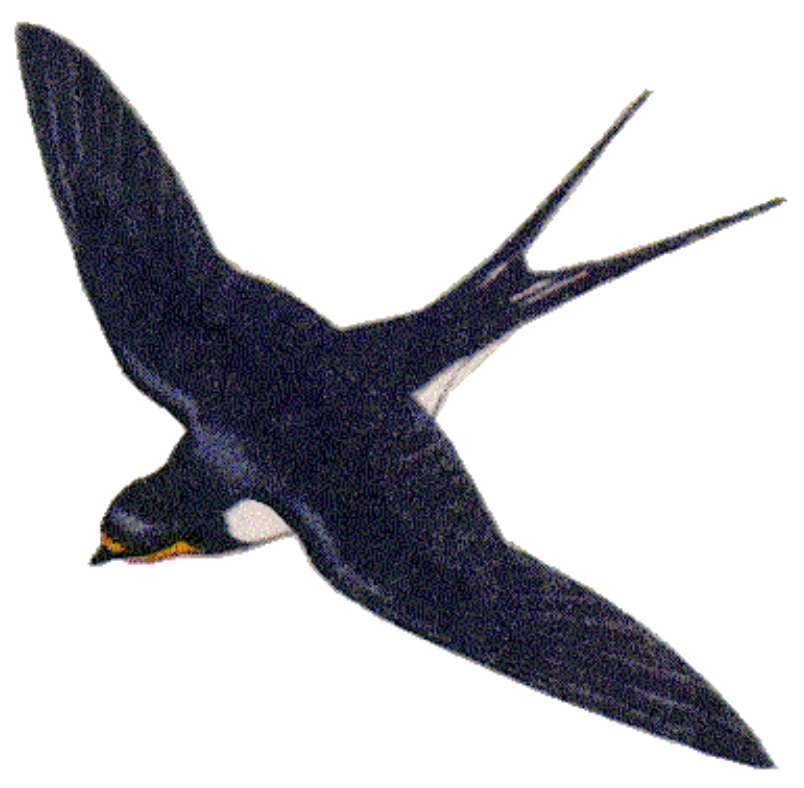

4. Võõrasema tapab vaeslapse, luudest saab pääsuke (vrd. AT 720);

pääsuke Hirundo rustica, Delichon urbica. Enamik tekke- ja seletusmuistendeid pääsukestest lähtub mingist ülekohtuaktist naisterahva (tüdruku, nooriku) vastu, kellest saab pääsuke:

1. Abielumees võtab uue, noorema naise. Eelmine lendab pulmast pääsukesena minema;

2. Mees võtab naise, kes ei kõnele, tahab teda vihahoos tappa ja lööb tal kirvega seelikusaba lõhki. Naine lendab pääsukesena minema;

3. Nõid (võõrasema) muudab pruudi pääsukeseks ja paneb oma tütre asemele. Pääsuke oma laulus teatab tõe, mispeale ta välja kihutatakse. Lõhkilöödud saba saab ta pulmamõõga hoobi tõttu;

5. Võõrasema tahab vaeslast tappa, see pääseb verise kurgualuse ja lõhkise seelikuga ning saab pääsukeseks;

6. Ämm lööb minial saba lõhki;

7. Pääsuke on saanud orjatüdrukust, kel olnud vähe süüa ja palju tööd, sest ajast on tal must rätt õlgadel;

8. Jumal (sant, nõid) muudab rikka talu pulmaseltskonna pääsukesteks.

Päsakese sabaharude saamislugusid on veel: selle eest, et pääsuke inimest kaitses, hammustas madu tal tüki sabast välja; pääsuke jäi aiateiba otsa kinni; naeris enda saba lõhki.

Pääsukest on nimetatud ka jumala kanaks (lutsi keelesaare eestlased) või Jeesuse linnuks, seletusega, et Jeesus lapsena teinud savist lindusid ja neist saanud pääsukesed.

Pääsukeste elutsemist maja juures on peetud hea õnne märgiks. Pääsupesa mahakukkumine, päsukeste loobumine pesitsemisest maja juures tähendas loomaõnnetust, tulekahju, tüli, pahandust, koguni majaomaniku surma. Inimelamusse sisse lendamist pole heaks endeks peetud, see kuulutab ette tulekahju või pereliikme surma, harvemini pulmi. Lehma kõhu alt läbi lendamine arvati nagu *lepalinnu lendamisestki, et lehm hakkab verd lüpsma. Üks raviviise on tulel suitsutatud pääsupesa sisseandmine haigele loomale. Päs̈supesa lõhkumisel ootab ees õnnetus, pimedaks jäämine, lapsepea kasvab pääsupea taoliseks, kariloomadel jäävad jalad haigeks, lehm hakkab verd lüpsma, surevad lambad, linnukasvatus ei õnnestu või läheb maja põlema. Lääne- ja Pärnumaal öeldi, et lõhkuja näole ilmuvad pääsukesetäpid (tedretähed). Pääsukest keelati puutuda, öeldi, et kui inimene teda puutub, siis see lind elama ei jää ja varsti hukkub (Kodavere). Tuntud on muistend, et pääsukesed on talvel järves ning söövad enne erilist taime, et kevadeni magama jääda (analoogia *madude talvekorterisse jäämisega).

Rahvauskumuse järgi talvituvad pääsukesed järves, suurte veekogude kallastes, kõrkjates või vees (jalgupidi kimbus, üksteise sabas kinni). Ka on öeldud, et ta reisib *sookure jt. suurte lindude 
sulgede sees või saba peal. Saabumisaega on dateeritud künnipäevaga 14.IV, jüripäevaga 23.IV, volbripäevaga 1.V. Esimeste nn. maakuulutajate saabumise järel arvati ilma külmaks minevat (pääsukesetalv). Ilmade soojenemist märgib vanasõna: *Lõoke toob lõunasooja, pääsuke päevasooja, *ööbik öösooja.

Esmakordne nägemine kevadel on tähenduslik. Sümboolikat: lennus - peavalu, peapööritust (Võrumaa); paarisarv - pulmi; häälitsemine - sead sigivad hästi (Pärnumaa). Tartu- ja Võrumaal on soovitatud pääsukese esmakordsel nägemisel uperpalli visata, et suvel seljavalu poleks. Pesa rajamine on külviorientiir: "Kui pääsukesel on pesas kaks muna, siis külva kahe sõrme vahelt, kui viis, siis viie vahelt." Suvist lahkumist, pesitsuskohtadelt on dateeritud jakobipäevaga 25.VIII (varase rukkikülviaja enne) ning pärtlipäevaga 24.VIII (pika sügise enne).

Üldtuntud on ilmaenne: kui pääsukesed madalal lendavad, tuleb vihma, kui kõrgel, siis kuiva.

Populaarsuse tõttu rahvapärimustes ning kuuluvana maakodude juurde valiti suitsupääsuke 1992. a. Eesti rahvuslinnuks.

püü - vt. laanepüü

ristnokk - vt. käbilind

ronk (vt. kaaren)

rukkirääk Crex crex. Rukkiräägu asukoha järgi - kas heinamaal või põllul, on kogu maal tehtud otsustusi, kas oodata on head heinasaaki või viljasaaki. Ühes LääneNigula tekstis on nimetatud, et rukkis oli rääk nagu haldjaks, kui ta karjus, siis tähendas see head rukkisaaki.

Rahvauskumuse järgi rukkirääk, otsetõlkes rukkirääk, ei lenda, seepärast saabub ta soojalt maalt viimasena.

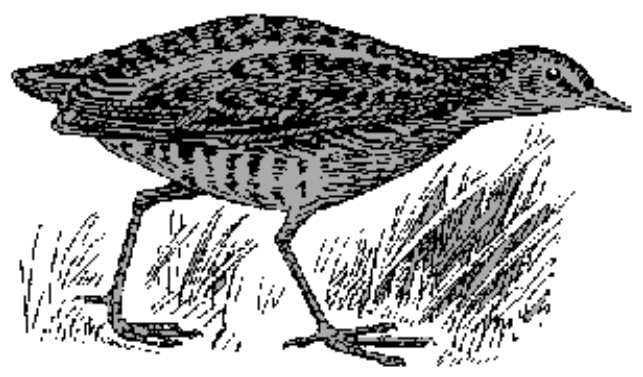
Seletused rände ja talvitumise kohta: kõnnib jala soojalt maalt kohale; üle vee pääseb laevade ja puunottide peal; rändab *toonekure seljas; muutub sügisel kulliks (analoogia *käoga); on talvel metsas küngaste all.

Kes kevadel *linnupetet võtmata, s.o. ilma söömata välja minnes rukkiräägust "petetud" sai, seda arvati suvel palju peeretavat.

\section{Kirjandus}

AT - Aarne, A.; Thompson, St. 1961: The Types of the Folktale, FFC nr. 184. Helsinki.

Hiiemäe, M. 1982. Ei tohi peale hingata. Uskumusi linnupesadest. Eesti Loodus, 6, 1k. 390-395.

Hiiemäe, M. 1983. Vares vaagub vihma. Eesti Loodus, 5, 1k. 313-314.

Hiiemäe, M. 1985. Linnud ilmaennetes. Eesti Loodus, 12, 1k. 792-797.

Loorits, O. 1949. Grundzüge des estnischen Volksglauben I. Lund, 1k. 355-359.

Loorits, O. 1954. Neue Beiträge zum Vogelbetrug-Motiv. Suomalais-ugrilaisen Seuran

Aikakauskirja 57, 1k. 1-19.

Mäger, M. 1967. Eesti linnunimetused. Tallinn.

Mäger, M. 1969. Linnud rahva keeles ja meeles. Tallinn. 
Oinas, F. J. 1984. Linnupete. Vargamäe tõde ja õigus. Esseid. Truth and Justice of Vargamäe and other Essays. (res. Cheating Bird, 1k. 257), Välis-Eesti \& EMP, 1k. 149-161.

Salve, K. 1992. Lorijal lõuvad, kuuljad kõrvad (Ida-Virumaa rahvajuttudest). Ida-Virumaa rahvakultuurist. Tallinn, 1k. 82-100.

Zelenin, D. 1938. Der alte estnische Brauch. den Vogelbetrug essen (linnupetet sööma). Litterarum societas Esthonica 1838-1938. Liber Saecularis II. Tartu, 1k. 865-879.

\section{Joonised ja pilditahvlid}

Kumari, E. 1974 Eesti lindude välimääraja. Tallinn.

Kumari, E. 1984 Eesti lindude välimääraja. Tallinn.

\section{Helinäited}

Helinäited pärinevad Eesti Raadio arhiivist. Kasutatud on Fred Jüssi ja B. Veprintsevi salvestusi, plaate "British Bird Songs and Calls", kassette "Maaseutulinnut", "Lapin kevät ja kesä", "Laulava lintukirja". Täname abi eest Toomas Jüriadot. 